OPEN ACCESS

Edited by:

Heiko Mühl,

Goethe University Frankfurt, Germany

Reviewed by:

Michael Paul Gantier,

Hudson Institute of Medical Research,

Australia

Patricia Fitzgerald-Bocarsly,

The State University of New Jersey,

United States

*Correspondence:

Clara Taffoni

clara.taffoni@igh.cnrs.fr

Nadine Laguette

nadine.laguette@igh.cnrs.fr

Specialty section:

This article was submitted to

Inflammation,

a section of the journal

Frontiers in Immunology

Received: 29 January 2021 Accepted: 18 March 2021

Published: 26 April 2021

Citation:

Taffoni C, Steer A, Marines J, Chamma H, Vila IK and Laguette $N$

(2021) Nucleic Acid Immunity and DNA Damage Response:

New Friends and Old Foes.

Front. Immunol. 12:660560. doi: 10.3389/fimmu.2021.660560

\section{Nucleic Acid Immunity and DNA Damage Response: New Friends and Old Foes}

\author{
Clara Taffoni $^{1 *}$, Alizée Steer ${ }^{1}$, Johanna Marines ${ }^{1,2}{ }^{\text {, Hanane Chamma }}{ }^{1}$, Isabelle K. Vila ${ }^{1}$ \\ and Nadine Laguette ${ }^{1 *}$ \\ ${ }^{1}$ Institut de Génétique Humaine, CNRS, Université de Montpellier, Molecular Basis of Inflammation Laboratory, Montpellier, \\ France, ${ }^{2}$ Azelead, Montpellier, France
}

The maintenance of genomic stability in multicellular organisms relies on the DNA damage response (DDR). The DDR encompasses several interconnected pathways that cooperate to ensure the repair of genomic lesions. Besides their repair functions, several DDR proteins have emerged as involved in the onset of inflammatory responses. In particular, several actors of the DDR have been reported to elicit innate immune activation upon detection of cytosolic pathological nucleic acids. Conversely, pattern recognition receptors (PRRs), initially described as dedicated to the detection of cytosolic immune-stimulatory nucleic acids, have been found to regulate DDR. Thus, although initially described as operating in specific subcellular localizations, actors of the DDR and nucleic acid immune sensors may be involved in interconnected pathways, likely influencing the efficiency of one another. Within this mini review, we discuss evidences for the crosstalk between PRRs and actors of the DDR. For this purpose, we mainly focus on cyclic GMP-AMP (cGAMP) synthetase (cGAS) and Interferon Gamma Inducible Protein 16 (IFl16), as major PRRs involved in the detection of aberrant nucleic acid species, and components of the DNA-dependent protein kinase (DNA-PK) complex, involved in the repair of double strand breaks that were recently described to qualify as potential PRRs. Finally, we discuss how the crosstalk between DDR and nucleic acid-associated Interferon responses cooperate for the fine-tuning of innate immune activation, and therefore dictate pathological outcomes. Understanding the molecular determinants of such cooperation will be paramount to the design of future therapeutic approaches.

Keywords: cytosolic nucleic acids, DNA damage responses, inflammation, cGAS-STING, IFI16, DNAPK, tumorigenesis

\section{INTRODUCTION}

Innate immunity, the first line of host defense, is classically triggered in response to pathogen infection or local lesions to promote infection clearance or wound-healing processes. The activation of innate immune responses vastly relies on pattern-recognition receptors (PRRs) that detect danger associated molecular patterns (DAMPs) or pathogen-associated molecular patterns (PAMPs). Upon recognition of PAMPs or DAMPs, PRRs trigger signaling cascades leading to the production of 
soluble mediators, such as type I Interferons, cytokines and chemokines. Pathogen-derived nucleic acids constitute major PAMPs that are detected by a vast array of PRRs that operate in specific subcellular localizations. In recent years, self-nucleic acids, originating from replication stress (1), DNA or mitochondrial damage (2), and endogenous retroelement activation (3), have been identified as substrates for cytosolic PRRs, and are thus considered as DAMPs. Because nucleic acids are abundant in cells, the activity of PRRs engaged in their detection is regulated and compartmentalized (4). PRRs dedicated to nucleic acid detection also present substrate specificity, with subclasses dedicated to the detection of particular moieties (5).

A plethora of cytosolic nucleic acid sensors have been described to participate in triggering Interferon responses. Such receptors notably include the ubiquitous DNA-dependent activator of Interferon regulatory factors (DAI) (6), AIM2 (7, 8), Interferon gamma-inducible protein 16 (IFI16) (9), melanoma differentiation factor 5 (MDA5) (10) and retinoic acid-inducible gene (RIG-I) (10). An extensive description of the mechanism of action of the above mentioned PRRs can be found in (11). Among pathways involved in cytosolic nucleic acid detection, the Stimulator of Interferon genes (STING) protein constitutes a central signaling hub $(12,13)$. Initial reports indicated that STING activation requires detection of cytosolic nucleic acid species such as double strand (dsDNA), single strand (ssDNA), or RNA : DNA species (14-16) by the cyclic GMP-AMP (cGAMP) synthase (cGAS) PRR (14). The main signature of activation of this signaling pathway is the production of type I Interferons that in turn promote the production of interferonstimulated genes (ISGs). This signaling pathway has attracted tremendous biomedical interest in recent years, notably with observation that agonists of STING can boost antitumoral immunity (17).

However, there is emerging evidence for an intricate signaling network beyond the cGAS-STING cascade, which cannot be overlooked in therapeutic strategies aiming to boost STING activation. Of particular importance is the fact that cGAS and STING have been both described as involved in genotoxic stress response and to participate to the maintenance of genomic integrity. Furthermore, the DNA-PK complex, which is best known for its function in non-homologous end-joining (NHEJ)mediated repair of dsDNA breaks (DSB), has been shown to serve as an alternative route to stimulate type I Interferon production (18-21). In parallel, the Interferon Gamma Inducible Protein 16 (IFI16) was also reported to detect, in concert or not with cGAS, DNA damage-derived nucleic acid species $(9,22,23)$, and to cooperate with DDR proteins to promote STING-dependent immune responses following genotoxic stress (22). Furthermore, cGAS and STING have been shown to control genomic stability $(24,25)$. Thus, the current literature highlights tight connections between DNA repair processes and nucleic acid-associated inflammatory responses. Indeed, proteins involved in the recognition of abnormal DNA, regardless of their origin, appear to possess common roles in the initiation of inflammatory responses and surveillance of genomic integrity.
In this mini review, we discuss this interconnection between DNA repair mechanisms and nucleic acid immunity, by focusing on the cGAS and IFI16 receptors and the way in which they control STING activation. While several DNA repair proteins have been involved in the fine tuning of inflammatory responses $(22,26)$, here we focus on the DNA-PK complex, responsible for NHEJ, for which a role in controlling nucleic acid-dependent inflammatory responses has been reported (26). We discuss how dissecting these signaling networks will deepen our understanding of Interferon responses, which is likely crucial to the design of therapeutic responses to pathological inflammation.

\section{CYTOSOLIC NUCLEIC ACID DETECTION: STING AS A CENTRAL SIGNALING HUB}

\section{The cGAS-STING Pathway}

The production of type I Interferons, in the presence of cytosolic nucleic acid species, was initially described to rely mostly on cGAS (14). Indeed, cGAS detects dsDNA, ssDNA, or RNA : DNA species (14-16) in the cytosol and catalyzes the synthesis of cGAMP (Figure 1A). Although the binding of cGAS to nucleic acid species is sequence-independent, cGAS activation is increased by longer dsDNA fragments $(27,28)$, suggesting that portions of chromosomes, such as those arising in the micronucleation process, would serve as potent substrates for cGAS. cGAMP interacts with the endoplasmic reticulum (ER)resident STING adaptor protein $(29,30)$, promoting conformational changes $(29,31)$, oligomerization (32) and translocation to perinuclear compartments, including the Golgi apparatus $(12,33)$. Subsequent recruitment of the TANKbinding kinase 1 (TBK1) (34), together with transcription factors, such as Nuclear Factor Kappa B (NF- $\kappa B)$ and Interferon Response Factor 3 (IRF3), ultimately leads to the transcription of a repertoire of inflammatory cytokines characterized by a type I Interferon signature $(12,35)$ (Figure 1A). NF- $\kappa B$ activation may also be promoted by IKKe, in addition to TBK1, in macrophages (36). The cGAS-STING cascade is triggered upon cytosolic exposure of foreign nucleic acid species, following pathogen infection, but also by nucleusand mitochondria-derived self-nucleic acids that leak into the cytosol following various types of stress $(2,37-40)$ and through DNA recombination processes (41).

Yet, the cGAS-cGAMP-STING signaling axis has recently emerged as far more complex than initially anticipated. First, multiple post-translational modifications influence signaling output (42-44). Second, STING can be directly activated by bacterial cyclic di-nucleotides $(45,46)$, while its activation is skewed by alternative di-nucleotides (16) or other metabolites (47). Third, co-sensors, co-factors and alternative upstream STING activators have been described, that can operate in cell type-specific manners $(23,48-50)$. Finally, in addition to the cellautonomous capacity of cGAMP to activate STING-dependent Interferon responses, cGAS-STING signaling may also be amplified through transfer of cGAMP to neighboring cells 


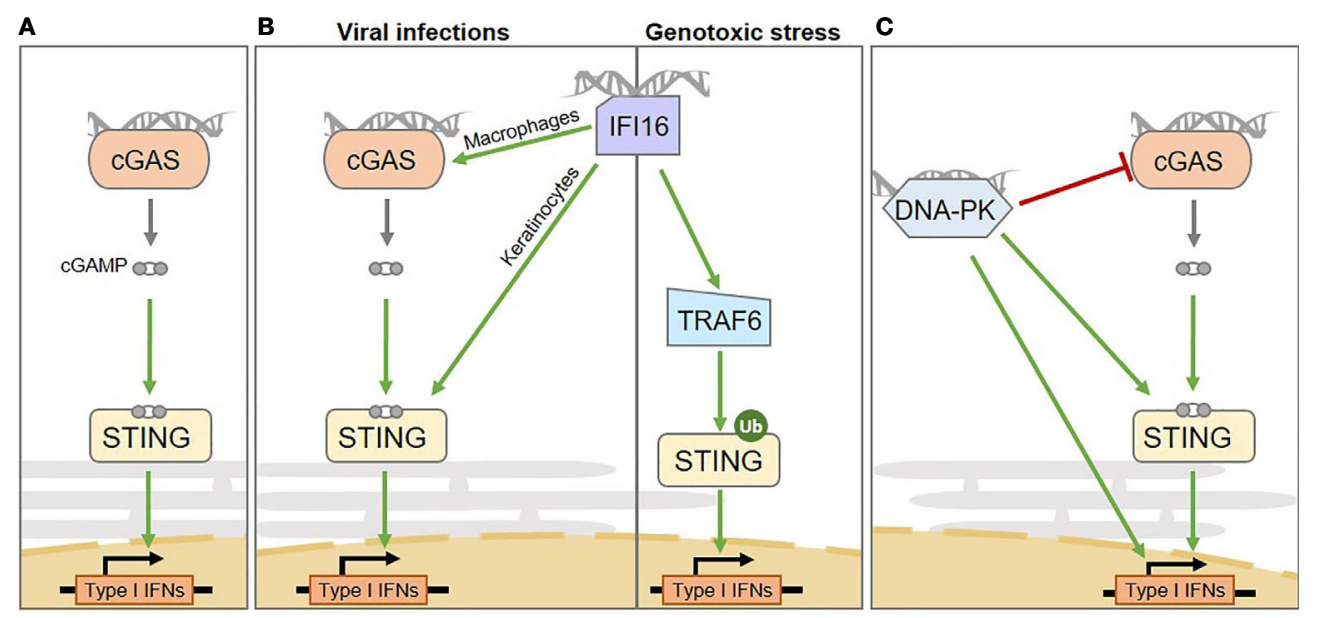

FIGURE 1 | Intertwined cytosolic nucleic acid pathways involved in Interferon and pro-inflammatory cytokine production in human cells. (A) The cGAS sensor activates STING via the production of the cGAMP second messenger. (B) From left to right: the IFI16 sensor mediates inflammation through multiple routes: upon viral infection it activates STING in a cell type-specific manner, either enhancing cGAS-dependent cGAMP production in macrophages or by directly activating STING in keratinocytes; upon genotoxic stress it mediates cGAS-independent, but TRAF6-dependent STING activation. (C) the DNA-PK DNA repair complex was shown to play a role in inducing type I Interferon production upon cytosolic dsDNA detection. However, multiple downstream mechanisms have been proposed, that require STING activation or not, ultimately leading to the phosphorylation of transcription factors responsible for type I Interferon production. The catalytic subunit of the DNA-PK complex (DNA-PKcs) can also suppress cGAS enzymatic activity, by promoting its phosphorylation. IFNs, Interferons.

through gap junctions (51-53), direct secretion (54) or in vesicles (55).

Below, we focus on IFI16 and DNA-PK as alternative sensors involved in the regulation of STING-dependent Interferon responses.

\section{IFI16: An Alternative Nucleic Acid Sensor}

IFI16 is a predominantly nuclear protein that has been described as involved in the induction of innate immune responses upon infection by viruses, including Herpes simplex virus (9), EpsteinBarr virus (56), and Kaposi's sarcoma-associated Herpes virus (57). Indeed, in this context, IFI16 promotes IRF3- and NF- $\kappa B-$ dependent Interferon production via STING (9) (Figure 1B). Similar to cGAS, IFI16 is capable of detecting self and non-self DNA, and displays a preference for long non-self dsDNA (58). Unlike cGAS, IFI16 operates mostly in a cell-type-dependent manner $(23,50)$. The interplay between cGAS and IFI16 has been explored, revealing cooperation between IFI16 and cGAS upon infection (Figure 1B, left). This cooperation relies on celltype specific molecular mechanisms. Indeed, in both keratinocytes and macrophages, IFI16 cooperates with cGAS for STING activation upon infection $(23,50)$. However, in macrophages, IFI16 enhances cGAS-dependent cGAMP production (50), while in keratinocytes, IFI16 does not influence cGAMP production, but rather directly activates STING (23). Additionally, IFI16 has been shown to promote inflammasome activation in the nucleus, leading to production of Interleukin-1 $\beta$ (IL-1 $\beta$ ), IL-18, and IL-33 cytokines $(56,59)$.

In contrast, following genotoxic stress, IFI16 triggers cGASindependent STING activation (Figure 1B, right). Indeed, upon etoposide-induced DNA lesions, IFI16, together with DDR proteins, activates STING, promoting the assembly of a non- canonical STING signalosome (22). Within this complex IFI16 promotes TNF Receptor Associated Factor 6 (TRAF6)dependent STING ubiquitination and activation ultimately leading to the predominant activation of the transcription factor $\mathrm{NF \kappa B}$, rather than IRF3 (22). Therefore, this signaling cascade results in the expression of a repertoire of cytokines that differs from that triggered upon cGAS-mediated detection of dsDNA, including a specific IL-6 and CCL20 signature (22). Yet, most of the described mechanisms were inferred from the study of keratinocytes or myeloid cell lines, leaving uncertainties concerning the activation of IFI16 in cancer cells.

\section{DNA-PK: Bridging DNA Repair and Nucleic Acid Immunity}

The DNA-PK complex has been reported to play a role in controlling nucleic acid-dependent inflammation. The DNA$\mathrm{PK}$ complex is a key holoenzyme, composed of KU70 ${ }^{\mathrm{XRCC} 6}$, KU80 ${ }^{\mathrm{XRCC} 5}$ and the DNA-dependent protein kinase catalytic subunit DNA-PKcs ${ }^{\text {PRKDC }}$, central to the repair of DSBs by NHEJ. NHEJ is involved in the repair of approximately $80 \%$ of DSBs and can operate regardless of the cell cycle phase. It promotes relegation of DNA ends without requirement for an intact template (60). KU70/KU80 heterodimers interact directly with damaged DNA ends and are responsible for the recruitment of DNA-PKcs to these lesions. DNA-PKcs bears a kinase activity and promotes both DNA-PKcs autophosphorylation and the phosphorylating-activation of effector proteins required for the NHEJ process. For a complete recent view of NHEJ refer to (61).

Besides its canonical role in NHEJ while it recognizes self dsDNA, there are several reports for a central role of DNA-PK in the detection of exogenous DNA species and interference with 
viral life cycles (62). Subunits of the complex have been independently reported to trigger or skew inflammatory responses toward either type I or type III Interferon production in response to non-self dsDNA. Indeed, KU70 triggers DNA-dependent type III Interferon responses through activation of Interferon Regulatory Factor 1 and 7 (IRF1 and IRF7) (19, 63), independently of DNA-PKcs (19).

In contrast, recent reports indicate that the catalytic activity of DNA-PKcs is also crucial for antiviral responses. Indeed, DNAPKcs promotes IRF3 phosphorylation following infection by DNA and RNA viruses (18, 64) (Figure 1C). Interaction between DNA-PKcs and the progenome of the Human Immunodeficiency Virus (HIV) retrovirus has also been shown, although the link to inflammation is unexplored (65). Interestingly, some DNA viruses have evolved proteins that counteract DNA-PKcs-dependent detection (20) while others hijack NHEJ to the benefit of their replication (66), highlighting the tight interplay between viral life cycles and DDR (67). Yet, there is as of today, limited knowledge concerning the ways in which DNA-PK-dependent inflammatory responses, IFI16- and cGAS-dependent STING activation are orchestrated.

Indeed, whether DNA-PK requires STING for production of Interferons remains debated $(18,20,68)$ (Figure 1C). It was reported that DNA-PKcs is recruited to dsDNA in the cytoplasm of both human and murine cells through KU80, triggering IRF3dependent inflammatory responses (18). However, while some reports indicate that the catalytic activity of DNA-PKcs is responsible for direct activating phosphorylation of IRF3 (64), others indicate that the measured Interferon production can occur independently of the catalytic activity of DNA-PKcs (18). In this latter scenario, questions remain open concerning what would trigger IRF3 activation. It has also been proposed that DNA-PKcs would act upstream of TBK1 and IRF3 (18) and that KU70 can form a complex with STING prior to (18), or upon (19) DNA transfection. This notion was comforted by Morchikh et al., in 2017, showing that DNA-PK subunits (DNA-PKcs, KU70 and KU80) are associated with a ribonuclear complex that is remodeled by foreign DNA, leading to enhanced recruitment of STING, activated DNA-PKcs, and IRF3 (68). However, a recent study has shown that DNA-PKcs can also operate independently of STING (20) and that DNA-PKcs can phosphorylate cGAS and suppresses its enzymatic activity (21) (Figure 1C). Considering the tight link between DNA-PK activation and cell cycle progression (69), and in view of the recent reports linking cGAS activation and cell cycle stage (70), the crosstalk between DNA-PK and cGAS-STING activation would certainly benefit from integrating the temporality of events to the study. In agreement, it was previously reported that inhibition of NHEJ components reduces Interferon signaling, in a cell cycle progression-dependent manner (71).

Adding a layer of complexity, DNA-PKcs immune signaling appears to be species-specific. Indeed DNA-PKcs can activate innate immune responses independently of STING in human cells, but not in murine cells (20). This is consistent with previous reports that in mouse cell lines, where the immune response is largely dependent on STING, DNA-PKcs would signal through
STING (18). Furthermore, the current state-of-the-art does not allow determining whether the role of DNA-PK in inducing type I Interferon responses may be subjected to cell type-specific regulatory mechanisms, as was reported for IFI16. In this respect, how IFI16 activation is regulated in contexts where DNA-PKcs activates inflammatory responses remains to be elucidated.

\section{REGULATION OF THE DNA DAMAGE RESPONSE BY INNATE IMMUNE SENSING PATHWAYS}

\section{cGAS Suppresses DNA Damage Responses}

The cGAS protein was initially identified as the main receptor for cytosolic nucleic acid moieties that promote type I Interferon responses (14). However, it was recently demonstrated that an abundant pool of cGAS is tethered to the chromatin, in absence of inflammatory stimulus (72-74). Active export of cGAS through the Chromosomal Maintenance 1 (CRM1) exportin was recently demonstrated, suggesting that shuttling of cGAS to the cytosol may be a prerequisite for its activation (75). However, the molecular mechanisms triggering cGAS nuclear export and whether cGAS may also be activated in the nucleus, remains to be clarified. There is evidence for a role of cGAS in the inhibition of Homologous Recombination (HR)-mediated repair of DSB. Contrary to NHEJ, that operates in a cell cycle stageindependent manner, HR requires the presence of the sister chromatid for accurate repair of DNA lesions (76) and therefore operates mostly during the G2/M phase of the cell cycle. HR is a complex, multistep process that can be completed through several interconnected pathways, for which a complete overview can be found in (77). Two mechanisms have been proposed for cGAS-dependent HR inhibition (Figure 2, left). On one hand, Liu et al. showed that DNA damage triggers cGAS nuclear translocation and interaction with activated DNA damage-dependent Poly [ADP-ribose] polymerase 1 (PARP1), which is a first responder in DNA damage detection. Interaction of cGAS with PARP1 prevents the recruitment of proteins required to proceed through $\mathrm{HR}$ process and does not require the cGAS DNA-binding domain (79). However, since the majority of cellular cGAS is nuclear (72-74), one may question why the cytosolic rather than the chromatinian pool of cGAS would be mobilized. This may be linked to the high affinity of cGAS for the acidic patch of histones that renders chromatinian cGAS not easily displaceable (73). On the other hand, Jiang et al. observed that the DNA-binding domain of chromatin-bound cGAS is crucial for cGAS oligomerization on DNA, hindering the formation of displacement loops, which are required for HR to proceed (80). Consequently, upon irradiation, cells expressing cGAS present increased accumulation of DSBs as compared to cells that do not express cGAS. Intriguingly, this function is reportedly independent of cGAS-mediated innate immune sensing (80). 


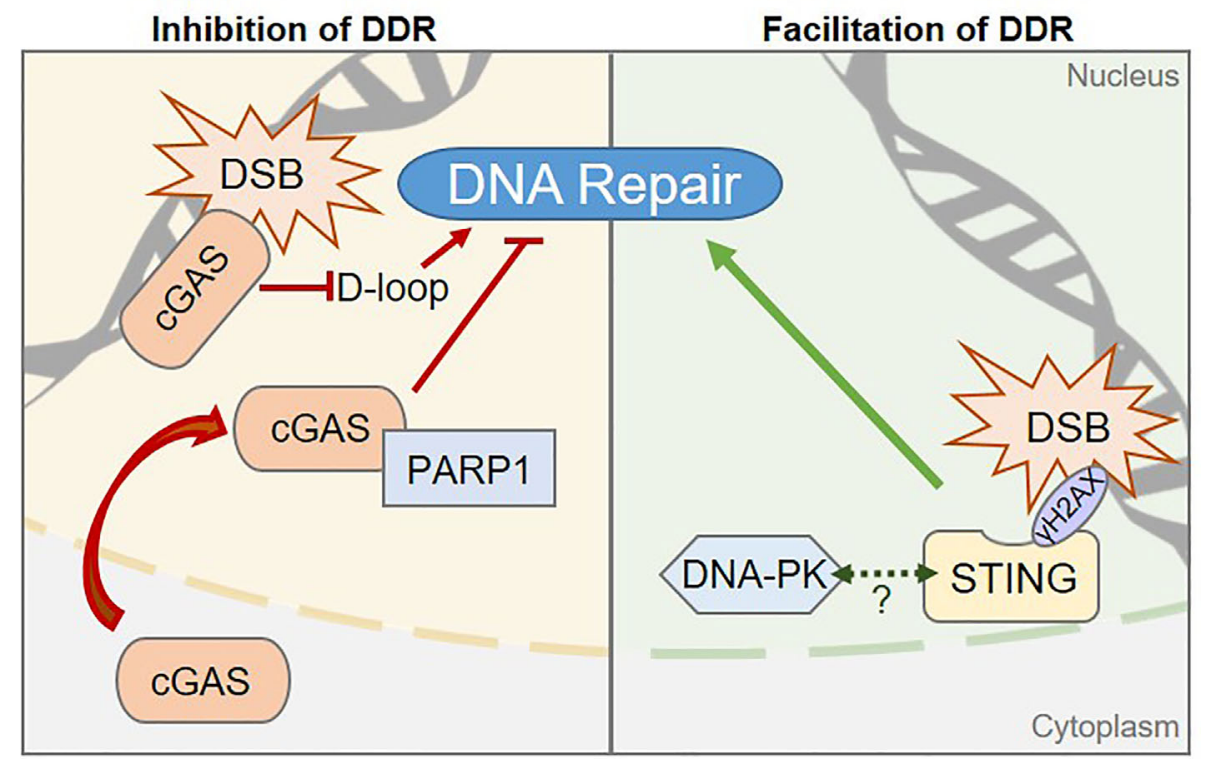

FIGURE 2 | Pattern Recognition Receptors are involved in regulating DNA damage repair processes. Left, The cGAS sensor can inhibit DNA Damage Responses (DDR) via two distinct mechanisms in human cells: 1) cGAS inhibits the Homologous Recombination (HR) pathway by preventing displacement loop (D-loop) formation. 2) cGAS-PARP1 interaction impedes the formation of a PARP1-based complex required for HR-mediated DNA repair. Right, STING promotes DDR in human cells through a yet to be elucidated molecular mechanism, but may rely on the control of components of the Non-Homologous End Joining DNA repair pathway, such as the DNA-PK complex. Dashed arrow between STING and DNA-PK represents the reported interaction between the two proteins (19, 68, 78). Whether this interaction is related to STING-associated DDR control is unknown.

\section{STING as a Promoter of DNA Damage Responses}

STING, the major downstream partner of cGAS, has been proposed to promote DDR and to enable cell survival, in an inflammation-independent manner (Figure 2, right). An important part of the regulation of STING activation is linked to its subcellular localization, with inactive STING resting in the ER and activation promoting its relocalization to the Golgi apparatus. Interestingly, in certain contexts, such as following chemotherapy regimens, STING colocalizes with $\gamma \mathrm{H} 2 \mathrm{AX}$ positive DNA damage foci, at the inner nuclear membrane (78). In addition, cells knocked-down for STING present accumulation of DNA damage as compared to WT cells (78). No clear molecular mechanism has been proposed yet, although STING has been demonstrated to interact with NHEJ proteins, including DNA-PKcs, KU70 and KU80 $(18,19,68,78)$, suggesting that it may participate directly in the regulation of NHEJ. Moreover, STING overexpression leads to increased binding of DNA-PK to chromatin, suggesting that STING may cooperate with DNA-PK to control NHEJ-mediated DNA repair (78). However, the contribution of STING to NHEJ efficiency was not addressed, calling for further investigation.

Altogether, the subcellular localization of PRRs is central to the regulation of their activity, and determines whether they mediate repair- or immune-related functions. This is similar to what is witnessed for components of DNA-PK that are engaged in DNA repair or innate immune activation, depending on their subcellular localization and interactors. How these pathways cooperate or antagonize each other in given pathological situations, and in particular in the case of genotoxic stress that induces both repair and immune activation, remains to be elucidated.

\section{COOPERATION BETWEEN DDR AND INNATE IMMUNITY IN TUMORIGENESIS}

The interplay between innate immune activation and DNA repair pathways is likely to be central to our understanding of several human pathologies. For instance, several cancer susceptibility syndromes, such as Fanconi Anemia, that present with inheritable deficiencies in DNA repair pathways also display hematological disorders, such as bone marrow failure or autoimmunity, together with elevated type I Interferon levels. Mutations in DNA repair proteins are also found in diseases primarily defined as auto-inflammatory as described thoroughly in Ragu et al. (26). Indeed, deficient DDR frequently leads to pathologies, such as Ataxia-Telangiectasia, Werner Syndrome and Bloom Syndrome, in which inflammation plays a great part (81-83). Likewise, chronic inflammation plays an important role in all stages of sporadic cancer, from the onset of neoplastic lesions to metastatic dissemination (84).

Although STING targeting immunotherapies have seen a huge biomedical interest in recent years, the study of the 
impact of STING activation on tumorigenesis has revealed an extremely complex relationship with tumor fate. In many cases STING activation has been shown to promote tumor clearance. Nucleic acid substrates for cGAS in tumors can result from the release of chromatin fragments in the cytosol of tumor cells (85), leading to cGAS-STING activation and cell cycle arrest (85-87). In addition, released self-DNA, from dying tumor cells in the tumor microenvironment can be engulfed by intra-tumoral antigen-presenting cells (APCs), such as dendritic cells and macrophages and likely activates the cGAS-STING pathway (88), through mechanisms that are still under debate (89). The resulting cGAS-STING pathway activation promotes maturation and cross-presentation (90), ultimately leading to the recruitment and the infiltration of cytotoxic CD8(+) T cells at the tumor site $(91,92)$. Moreover, tumor-derived cGAMP promotes immune cells infiltration (52). Importantly, the cGAS-STING pathway was shown to potentiate the response to radiotherapy and chemotherapy $(88,93)$ and to synergize with checkpoint inhibitors $(94,95)$. Thus, activating the cGAS-STING axis in combination with chemotherapy and/or immunotherapy appears as a valuable therapeutic strategy.

However, there is evidence that cGAS-STING-dependent inflammation can fuel tumorigenesis (96), promote tolerogenic responses, impair the establishment of long-term immunity (97) and lead to chemoresistance $(98,99)$. Indeed, transfer of cGAMP from metastatic cells to astrocytes through gap junctions was also shown to support metastatic dissemination and chemoresistance (100). Finally, accumulation of micronuclei in the cytoplasm of cancer cells following ionizing radiation promotes STINGdependent inflammation $(40,71)$ and metastasis (101). It has been proposed that tumor grade and origin may account for these differential outcomes following cGAS-STING stimulation, calling for stratification strategies to identify patients that would benefit from cGAS-STING targeting immunotherapies.

Moreover, present therapeutic regimens include the use of DDR inhibitors in combination or not with radiotherapy (94, 102-104). Indeed, this approach induces accumulation of inflammatory cytosolic nucleic acids, leading to cGAS-STING pathway activation $(95,105)$ and promoting $\mathrm{T}$ cell infiltration and thus tumor regression $(95,102)$. Significant tumor regression has also been observed using DNA-PKcs inhibitors in combination with chemotherapy or radiotherapy (69), however the role of inflammation in this process is at present unexplored. Considering the emerging role of DDR proteins in innate immune responses, it is tempting to speculate that upon genotoxic stress, DDR proteins may directly fuel cancer-related inflammatory responses. In addition, numerous tumors down regulate the expression of cGAS and/or STING $(106,107)$. In these contexts, it would be important to examine if DDR proteins may take over the production of inflammatory cytokines.

Furthermore, STING activation has been shown to promote two distinct transcriptional programs. On one hand, activation of genes under the control IRF-3, leads mostly to the production of type I Interferons that are generally accepted as acting anti-cancer agents (108), while NF- $\mathrm{B}$ activation promotes the production of cytokines that are mostly considered pro-tumorigenic, such as IL-6 (109, 110). Indeed, increased plasma levels of IL-6 generally negatively correlate with patient survival in many cancers (110). It would be crucial to determine whether the differential outcomes of STING activation observed in studies describing STING activation as pro-tumorigenic would result from IL-6 secretion. Ultimately, it would be crucial to determine, in those contexts where alternative receptors to cGAS would potentiate STING-dependent signaling, whether they would lead to skewing of the response toward IL-6 production and promote pathological outcomes.

Reciprocally, regulation of DDR by PRRs is likely to affect tumorigenesis. HR inhibition by chromatin-bound cGAS accelerates genome destabilization and micronuclei generation, leading to cell death both in vitro and in vivo (80). Thus, cGAS may thereby restrict the propagation of cancer cells. To the contrary, alterations of cGAS shuttling toward the cytosol correlate with poor patient prognosis (79). This suggests that nuclear translocation of cGAS and subsequent HR inhibition may promote tumorigenesis (79), although this may also be linked to defective cGAS-dependent Interferon responses. Furthermore, IFI16 has also been reported to present nuclear functions $(57,111)$, including a role in regulation of cell cycle arrest $(111,112)$. Supporting an association between IFI16 and tumorigenesis, IFI16 levels are frequently decreased in breast cancer cell lines (113). Yet, there is as of today no clear implication of IFI16-dependent cytokine production in tumorigenesis. This leaves open the possibility that IFI16 may be mobilized in tumors where cGAS expression is downregulated. Thus, deciphering the molecular cues leading to the mobilization of the different pools of cGAS, or alternative receptors such as IFI16, to detect immune-stimulatory DNA and the impact of the different PRRs in DNA damage responses is likely primordial to the understanding of how nucleic acid detection dictates tumor fate.

\section{DISCUSSION}

Accumulation of cytosolic nucleic acids, including ssDNA, dsDNA and RNA : DNA hybrids, has been documented in several etiologically distinct human pathologies that present with pathological type I Interferon responses (114). Importantly, the range of symptoms experienced by patients is broad, and as of today not fully understood.

Much attention was brought to the cGAS-STING axis, notably because it was shown that cGAS is non-dispensable for STING activation in vivo. Indeed, in cells, including dendritic cells, macrophages or fibroblasts, from cGAS-deficient mice, nucleic acid-dependent STING activation was abolished (115). Yet, recent research has underlined the existence of speciesspecificities in innate immune detection of nucleic acids (116). Thus, although the cGAS-STING cascade represents a crucial cytosolic dsDNA detection route, a more complex picture is currently emerging. In addition to the many direct regulators of the cGAS-STING pathway, alternative receptors such as IFI16 and DNA-PK, may mediate stimulus-specific Interferon 
responses. Therefore, previously overlooked nucleic acid sensors should be re-examined (117). In particular, the recently uncovered cooperation between DDR and nucleic acid immunity can be expected to contribute to the health alterations witnessed in patients presenting with chronic inflammation while feeding cancer susceptibility directly.

Importantly, in inflammatory pathologies, it is generally considered a risky approach to directly act on pathways responsible for Interferon production (118). This is intrinsically linked to the duality of the impacts of Interferons, that can either be beneficial or promote cytopathic effects, depending on multiple parameters that are as of today poorly understood. Several chronic inflammatory pathologies, presenting with type I Interferon overproduction, such as type I Interferonopathies, or Aicardi-Goutières Syndromes are treated with inhibitors of the Janus kinase 1, 2 and 3 (119). This treatment, rather that halting Interferon production, prevents the induction of ISGs following the interaction of Interferons with its cognate receptor. However, such disruption of immune pathways comes at the expense of increased risk of infection (119). Identification of pathways responsible for activation of pathological immune responses and the design of specific targeting strategies may be valuable in these pathologies. Addressing whether DDR proteins are involved in the inflammatory signature present in these diseases is thus important.

Altogether, the current state-of-the-art supports that STING is an attractive target for the treatment of autoimmune, inflammatory diseases and cancer (17, 120). However, emerging regulators, cell type specific or stimulus specific responses, together with alternative functions of STING and its activators, indicate that our understanding of nucleic acid immunity is still in its infancy. Our view of how immunestimulatory DNAs are detected is likely grow in complexity, notably with the addition of DNA repair proteins to the list of PRRs. Therefore, the regulatory mechanisms and crosstalk

\section{REFERENCES}

1. Coquel F, Silva MJ, Techer H, Zadorozhny K, Sharma S, Nieminuszczy J, et al. SAMHD1 acts at stalled replication forks to prevent interferon induction. Nature (2018) 557:57-61. doi: 10.1038/s41586-018-0050-1

2. Rongvaux A, Jackson R, Harman CC, Li T, West AP, de Zoete MR, et al. Apoptotic caspases prevent the induction of type I interferons by mitochondrial DNA. Cell (2014) 159:1563-77. doi: 10.1016/j.cell.2014.11.037

3. Bregnard C, Guerra J, Dejardin S, Passalacqua F, Benkirane M, Laguette N. Upregulated LINE-1 Activity in the Fanconi Anemia Cancer Susceptibility Syndrome Leads to Spontaneous Pro-inflammatory Cytokine Production. EBioMedicine (2016) 8:184-94. doi: 10.1016/j.ebiom.2016.05.005

4. Barton GM, Kagan JC. A cell biological view of Toll-like receptor function: regulation through compartmentalization. Nat Rev Immunol (2009) 9:53542. doi: $10.1038 /$ nri2587

5. Chuenchor W, Jin T, Ravilious G, Xiao TS. Structures of pattern recognition receptors reveal molecular mechanisms of autoinhibition, ligand recognition and oligomerization. Curr Opin Immunol (2014) 26:14-20. doi: 10.1016/ j.coi.2013.10.009

6. Takaoka A, Wang Z, Choi MK, Yanai H, Negishi H, Ban T, et al. DAI (DLM-1/ZBP1) is a cytosolic DNA sensor and an activator of innate immune response. Nature (2007) 448:501-5. doi: 10.1038/nature06013 between engaged pathways will surely remain an area of intense research in coming years.

\section{AUTHOR CONTRIBUTIONS}

CT, AS, IV, HC, JM, and NL drafted and edited the manuscript. Visualization: IV. All authors contributed to the article and approved the submitted version.

\section{FUNDING}

Work in NL's laboratory is supported by grants from the European Research Council (ERC-Stg CrIC: 637763, ERC-PoC DIM-CrIC: 893772), "LA LIGUE pour la recherche contre le cancer" and the "Agence Nationale de Recherche sur le SIDA et les Hépatites virales” (ANRS). CT was supported by Merck Sharp and Dohme Avenir (MSD-Avenir - GnoSTic) program, followed by an ANRS fellowship (ECTZ119088). JM was supported by a "Conventions Industrielles de Formation par la Recherche" (CIFRE) fellowship from the "Agence Nationale de Recherche Technologie" (ANRT). AS is supported by the ERC-PoC DIMCrIC (893772). IV was supported by the European Research Council (637763) followed by the Prix Roger PROPICE pour la recherche sur le cancer du pancreas of the Fondation pour la Recherche Médicale (FRM, ARF20170938586). HC is supported by a PhD Fellowship from "La Ligue contre le cancer" (TAGQ21108). We acknowledge the SIRIC Montpellier Cancer Grant INCa_Inserm_DGOS_12553 for support.

\section{ACKNOWLEDGMENTS}

We thank C. Langevin for critical reading of the manuscript.

7. Hornung V, Ablasser A, Charrel-Dennis M, Bauernfeind F, Horvath G Caffrey DR, et al. AIM2 recognizes cytosolic dsDNA and forms a caspase-1activating inflammasome with ASC. Nature (2009) 458:514-8. doi: 10.1038/ nature 07725

8. Fernandes-Alnemri T, Yu JW, Datta P, Wu J, Alnemri ES. AIM2 activates the inflammasome and cell death in response to cytoplasmic DNA. Nature (2009) 458:509-13. doi: 10.1038/nature07710

9. Unterholzner L, Keating SE, Baran M, Horan KA, Jensen SB, Sharma S, et al. IFI16 is an innate immune sensor for intracellular DNA. Nat Immunol (2010) 11:997-1004. doi: 10.1038/ni.1932

10. Jiang $X$, Kinch LN, Brautigam CA, Chen X, Du F, Grishin NV, et al. Ubiquitin-induced oligomerization of the RNA sensors RIG-I and MDA5 activates antiviral innate immune response. Immunity (2012) 36:959-73. doi: 10.1016/j.immuni.2012.03.022

11. Unterholzner L. The interferon response to intracellular DNA: why so many receptors? Immunobiology (2013) 218:1312-21. doi: 10.1016/ j.imbio.2013.07.007

12. Ishikawa H, Ma Z, Barber GN. STING regulates intracellular DNAmediated, type I interferon-dependent innate immunity. Nature (2009) 461:788-92. doi: 10.1038/nature08476

13. Barber GN. STING: infection, inflammation and cancer. Nat Rev Immunol (2015) 15:760-70. doi: 10.1038/nri3921 
14. Sun L, Wu J, Du F, Chen X, Chen ZJ. Cyclic GMP-AMP synthase is a cytosolic DNA sensor that activates the type I interferon pathway. Science (2013) 339:786-91. doi: 10.1126/science.1232458

15. Kranzusch PJ, Lee AS, Berger JM, Doudna JA. Structure of human cGAS reveals a conserved family of second-messenger enzymes in innate immunity. Cell Rep (2013) 3:1362-8. doi: 10.1016/j.celrep.2013.05.008

16. Guerra J, Valadao AL, Vlachakis D, Polak K, Vila IK, Taffoni C, et al. LysyltRNA synthetase produces diadenosine tetraphosphate to curb STINGdependent inflammation. Sci $A d v$ (2020) 6:eaax3333. doi: 10.1126/ sciadv.aax 3333

17. Li A, Yi M, Qin S, Song Y, Chu Q, Wu K. Activating cGAS-STING pathway for the optimal effect of cancer immunotherapy. J Hematol Oncol (2019) 12:35. doi: 10.1186/s13045-019-0721-x

18. Ferguson BJ, Mansur DS, Peters NE, Ren H, Smith GL. DNA-PK is a DNA sensor for IRF-3-dependent innate immunity. Elife (2012) 1:e00047. doi: 10.7554/eLife.00047

19. Sui H, Zhou M, Imamichi H, Jiao X, Sherman BT, Lane HC, et al. STING is an essential mediator of the Ku70-mediated production of IFN-lambda1 in response to exogenous DNA. Sci Signal (2017) 10:488. doi: 10.1126/ scisignal.aah5054

20. Burleigh K, Maltbaek JH, Cambier S, Green R, Gale MJr., James RC, et al. Human DNA-PK activates a STING-independent DNA sensing pathway. Sci Immunol (2020) 5:43. doi: 10.1126/sciimmunol.aba4219

21. Sun X, Liu T, Zhao J, Xia H, Xie J, Guo Y, et al. DNA-PK deficiency potentiates cGAS-mediated antiviral innate immunity. Nat Commun (2020) 11:6182. doi: 10.1038/s41467-020-19941-0

22. Dunphy G, Flannery SM, Almine JF, Connolly DJ, Paulus C, Jonsson KL, et al. Non-canonical Activation of the DNA Sensing Adaptor STING by ATM and IFI16 Mediates NF-kappaB Signaling after Nuclear DNA Damage. Mol Cell (2018) 71:745-760 e5. doi: 10.1016/j.molcel.2018.07.034

23. Almine JF, O'Hare CA, Dunphy G, Haga IR, Naik RJ, Atrih A, et al. IFI16 and cGAS cooperate in the activation of STING during DNA sensing in human keratinocytes. Nat Commun (2017) 8:14392. doi: 10.1038/ ncomms 14392

24. Basit A, Cho MG, Kim EY, Kwon D, Kang SJ, Lee JH. The cGAS/STING/ TBK1/IRF3 innate immunity pathway maintains chromosomal stability through regulation of p21 levels. Exp Mol Med (2020) 52:643-57. doi: 10.1038/s12276-020-0416-y

25. Chen H, Chen H, Zhang J, Wang Y, Simoneau A, Yang H, et al. cGAS suppresses genomic instability as a decelerator of replication forks. Sci Adv (2020) 6:42. doi: 10.1126/sciadv.abb8941

26. Ragu S, Matos-Rodrigues G, Lopez BS. Replication Stress, DNA Damage, Inflammatory Cytokines and Innate Immune Response. Genes (Basel) (2020) 11:4. doi: 10.3390/genes 11040409

27. Luecke S, Holleufer A, Christensen MH, Jonsson KL, Boni GA, Sorensen LK, et al. cGAS is activated by DNA in a length-dependent manner. EMBO Rep (2017) 18:1707-15. doi: 10.15252/embr.201744017

28. Andreeva L, Hiller B, Kostrewa D, Lassig C, de Oliveira Mann CC, Jan Drexler D, et al. cGAS senses long and HMGB/TFAM-bound U-turn DNA by forming protein-DNA ladders. Nature (2017) 549:394-8. doi: 10.1038/ nature 23890

29. Zhang X, Shi H, Wu J, Zhang X, Sun L, Chen C, et al. Cyclic GMP-AMP containing mixed phosphodiester linkages is an endogenous high-affinity ligand for STING. Mol Cell (2013) 51:226-35. doi: 10.1016/ j.molcel.2013.05.022

30. Wu J, Sun L, Chen X, Du F, Shi H, Chen C, et al. Cyclic GMP-AMP is an endogenous second messenger in innate immune signaling by cytosolic DNA. Science (2013) 339:826-30. doi: 10.1126/science.1229963

31. Gao P, Ascano M, Zillinger T, Wang W, Dai P, Serganov AA, et al. Structurefunction analysis of STING activation by $\mathrm{cG}\left(2^{\prime}, 5^{\prime}\right) \mathrm{pA}\left(3^{\prime}, 5^{\prime}\right) \mathrm{p}$. and targeting by antiviral DMXAA. Cell (2013) 154:748-62. doi: 10.1016/j.cell.2013.07.023

32. Shang G, Zhang C, Chen ZJ, Bai XC, Zhang X. Cryo-EM structures of STING reveal its mechanism of activation by cyclic GMP-AMP. Nature (2019) 567:389-93. doi: 10.1038/s41586-019-0998-5

33. Saitoh T, Fujita N, Hayashi T, Takahara K, Satoh T, Lee H, et al. Atg9a controls dsDNA-driven dynamic translocation of STING and the innate immune response. Proc Natl Acad Sci USA (2009) 106:20842-6. doi: 10.1073/pnas.0911267106
34. Tanaka Y, Chen ZJ. STING specifies IRF3 phosphorylation by TBK1 in the cytosolic DNA signaling pathway. Sci Signal (2012) 5:ra20. doi: 10.1126/ scisignal.2002521

35. Abe T, Barber GN. Cytosolic-DNA-mediated, STING-dependent proinflammatory gene induction necessitates canonical NF-kappaB activation through TBK1. J Virol (2014) 88:5328-41. doi: 10.1128/ JVI.00037-14

36. Balka KR, Louis C, Saunders TL, Smith AM, Calleja DJ, D'Silva DB, et al. TBK1 and IKKepsilon Act Redundantly to Mediate STING-Induced NFkappaB Responses in Myeloid Cells. Cell Rep (2020) 31(1):107492. doi: 10.1016/j.celrep.2020.03.056

37. Tan X, Sun L, Chen J, Chen ZJ. Detection of Microbial Infections Through Innate Immune Sensing of Nucleic Acids. Annu Rev Microbiol (2018) 72:447-78. doi: 10.1146/annurev-micro-102215-095605

38. Klarquist J, Hennies CM, Lehn MA, Reboulet RA, Feau S, Janssen EM. STING-mediated DNA sensing promotes antitumor and autoimmune responses to dying cells. J Immunol (2014) 193:6124-34. doi: 10.4049/ jimmunol.1401869

39. Gao D, Li T, Li XD, Chen X, Li QZ, Wight-Carter M, et al. Activation of cyclic GMP-AMP synthase by self-DNA causes autoimmune diseases. Proc Natl Acad Sci USA (2015) 112:E5699-705. doi: 10.1073/ pnas. 1516465112

40. Mackenzie KJ, Carroll P, Martin CA, Murina O, Fluteau A, Simpson DJ, et al. cGAS surveillance of micronuclei links genome instability to innate immunity. Nature (2017) 548:461-5. doi: 10.1038/nature23449

41. Pepin G, Ferrand J, Honing K, Jayasekara WS, Cain JE, Behlke MA, et al. Cre-dependent DNA recombination activates a STING-dependent innate immune response. Nucleic Acids Res (2016) 44:5356-64. doi: 10.1093/nar/ gkw405

42. Hopfner KP, Hornung V. Molecular mechanisms and cellular functions of cGAS-STING signalling. Nat Rev Mol Cell Biol (2020) 21:501-21. doi: 10.1038/s41580-020-0244-x

43. Abe T, Shapira SD. Negative Regulation of Cytosolic Sensing of DNA. Int Rev Cell Mol Biol (2019) 344:91-115. doi: 10.1016/bs.ircmb.2018.09.002

44. Saeed A, Ruan X, Guan H, Su J, Ouyang S. Regulation of cGAS-Mediated Immune Responses and Immunotherapy. Adv Sci (Weinh) (2020) 7:1902599. doi: 10.1002/advs.201902599

45. Ergun SL, Fernandez D, Weiss TM, Li L. STING Polymer Structure Reveals Mechanisms for Activation, Hyperactivation, and Inhibition. Cell (2019) 178:290-301 e10. doi: 10.1016/j.cell.2019.05.036

46. Burdette DL, Monroe KM, Sotelo-Troha K, Iwig JS, Eckert B, Hyodo M, et al. STING is a direct innate immune sensor of cyclic di-GMP. Nature (2011) 478:515-8. doi: 10.1038/nature 10429

47. Vila IK, Chamma H, Steer A, Taffoni C, Reinert LS, Turtoi E, et al. Control of polyunsaturated fatty acids desaturation by Sting regulates inflammatory responses. bioRxiv (2020). doi: 10.1101/2020.12.22.423950

48. Wang X, Majumdar T, Kessler P, Ozhegov E, Zhang Y, Chattopadhyay S, et al. STING Requires the Adaptor TRIF to Trigger Innate Immune Responses to Microbial Infection. Cell Host Microbe (2016) 20:329-41. doi: 10.1016/j.chom.2016.08.002

49. Li Y, James SJ, Wyllie DH, Wynne C, Czibula A, Bukhari A, et al. TMEM203 is a binding partner and regulator of STING-mediated inflammatory signaling in macrophages. Proc Natl Acad Sci USA (2019) 116:16479-88. doi: 10.1073/pnas.1901090116

50. Jonsson KL, Laustsen A, Krapp C, Skipper KA, Thavachelvam K, Hotter D, et al. IFI16 is required for DNA sensing in human macrophages by promoting production and function of cGAMP. Nat Commun (2017) 8:14391. doi: 10.1038/ncomms14391

51. Ablasser A, Schmid-Burgk JL, Hemmerling I, Horvath GL, Schmidt T, Latz E, et al. Cell intrinsic immunity spreads to bystander cells via the intercellular transfer of cGAMP. Nature (2013) 503:530-4. doi: 10.1038/ nature 12640

52. Schadt L, Sparano C, Schweiger NA, Silina K, Cecconi V, Lucchiari G, et al. Cancer-Cell-Intrinsic cGAS Expression Mediates Tumor Immunogenicity. Cell Rep (2019) 29:1236-1248 e7. doi: 10.1016/j.celrep.2019.09.065

53. Pepin G, De Nardo D, Rootes CL, Ullah TR, Al-Asmari SS, Balka KR, et al. Connexin-Dependent Transfer of cGAMP to Phagocytes Modulates Antiviral Responses. mBio (2020) 11. doi: 10.1128/mBio.03187-19 
54. Carozza JA, Böhnert V, Nguyen KC, Skariah G, Shaw KE, Brown JA, et al. Extracellular cGAMP is a cancer-cell-produced immunotransmitter involved in radiation-induced anticancer immunity. Nat Cancer (2020) 1:184-96. doi: 10.1038/s43018-020-0028-4

55. Gentili M, Kowal J, Tkach M, Satoh T, Lahaye X, Conrad C, et al. Transmission of innate immune signaling by packaging of cGAMP in viral particles. Science (2015) 349:1232-6. doi: 10.1126/science.aab3628

56. Ansari MA, Singh VV, Dutta S, Veettil MV, Dutta D, Chikoti L, et al. Constitutive interferon-inducible protein 16-inflammasome activation during Epstein-Barr virus latency I, II, and III in B and epithelial cells. J Virol (2013) 87:8606-23. doi: 10.1128/JVI.00805-13

57. Kerur N, Veettil MV, Sharma-Walia N, Bottero V, Sadagopan S, Otageri P, et al. IFI16 acts as a nuclear pathogen sensor to induce the inflammasome in response to Kaposi Sarcoma-associated herpesvirus infection. Cell Host Microbe (2011) 9:363-75. doi: 10.1016/j.chom.2011.04.008

58. Morrone SR, Wang T, Constantoulakis LM, Hooy RM, Delannoy MJ, Sohn J. Cooperative assembly of IFI16 filaments on dsDNA provides insights into host defense strategy. Proc Natl Acad Sci USA (2014) 111:E62-71. doi: 10.1073/pnas.1313577111

59. Dutta D, Dutta S, Veettil MV, Roy A, Ansari MA, Iqbal J, et al. BRCA1 Regulates IFI16 Mediated Nuclear Innate Sensing of Herpes Viral DNA and Subsequent Induction of the Innate Inflammasome and Interferon-beta Responses. PloS Pathog (2015) 11:e1005030. doi: 10.1371/journal.ppat.1005030

60. Her J, Bunting SF. How cells ensure correct repair of DNA double-strand breaks. J Biol Chem (2018) 293:10502-11. doi: 10.1074/jbc.TM118.000371

61. Chang HHY, Pannunzio NR, Adachi N, Lieber MR. Non-homologous DNA end joining and alternative pathways to double-strand break repair. Nat Rev Mol Cell Biol (2017) 18:495-506. doi: 10.1038/nrm.2017.48

62. Schwartz C, Rohr O, Wallet C. Targeting the DNA-PK complex: Its rationale use in cancer and HIV-1 infection. Biochem Pharmacol (2019) 160:80-91. doi: 10.1016/j.bcp.2018.12.002

63. Zhang X, Brann TW, Zhou M, Yang J, Oguariri RM, Lidie KB, et al. Cutting edge: Ku70 is a novel cytosolic DNA sensor that induces type III rather than type I IFN. J Immunol (2011) 186:4541-5. doi: 10.4049/ jimmunol.1003389

64. Karpova AY, Trost M, Murray JM, Cantley LC, Howley PM. Interferon regulatory factor-3 is an in vivo target of DNA-PK. Proc Natl Acad Sci USA (2002) 99:2818-23. doi: 10.1073/pnas.052713899

65. Cooper A, Garcia M, Petrovas C, Yamamoto T, Koup RA, Nabel GJ. HIV-1 causes CD4 cell death through DNA-dependent protein kinase during viral integration. Nature (2013) 498:376-9. doi: 10.1038/nature12274

66. Frost JR, Olanubi O, Cheng SK, Soriano A, Crisostomo L, Lopez A, et al. The interaction of adenovirus E1A with the mammalian protein Ku70/XRCC6. Virology (2017) 500:11-21. doi: 10.1016/j.virol.2016.10.004

67. Bregnard C, Benkirane M, Laguette N. DNA damage repair machinery and HIV escape from innate immune sensing. Front Microbiol (2014) 5:176. doi: 10.3389/fmicb.2014.00176

68. Morchikh M, Cribier A, Raffel R, Amraoui S, Cau J, Severac D, et al. HEXIM1 and NEAT1 Long Non-coding RNA Form a Multi-subunit Complex that Regulates DNA-Mediated Innate Immune Response. Mol Cell (2017) 67:387-399 e5. doi: 10.1016/j.molcel.2017.06.020

69. Mohiuddin IS, Kang MH. DNA-PK as an Emerging Therapeutic Target in Cancer. Front Oncol (2019) 9:635. doi: 10.3389/fonc.2019.00635

70. Li T, Huang T, Du M, Chen X, Du F, Ren J, et al. Phosphorylation and chromatin tethering prevent cGAS activation during mitosis. Science (2021) 371. doi: 10.1126/science.abc5386

71. Harding SM, Benci JL, Irianto J, Discher DE, Minn AJ, Greenberg RA. Mitotic progression following DNA damage enables pattern recognition within micronuclei. Nature (2017) 548:466-70. doi: 10.1038/nature23470

72. Kujirai T, Zierhut C, Takizawa Y, Kim R, Negishi L, Uruma N, et al. Structural basis for the inhibition of cGAS by nucleosomes. Science (2020) 370:455-8. doi: 10.1126/science.abd0237

73. Michalski S, de Oliveira Mann CC, Stafford CA, Witte G, Bartho J, Lammens K, et al. Structural basis for sequestration and autoinhibition of cGAS by chromatin. Nature (2020) 587:6780-82. doi: 10.1038/s41586-020-2748-0

74. Pathare GR, Decout A, Gluck S, Cavadini S, Makasheva K, Hovius R, et al. Structural mechanism of cGAS inhibition by the nucleosome. Nature (2020) 587:668-72. doi: 10.1038/s41586-020-2750-6
75. Sun H, Huang Y, Mei S, Xu F, Liu X, Zhao F, et al. A Nuclear Export Signal Is Required for cGAS to Sense Cytosolic DNA. Cell Rep (2021) 34:108586. doi: 10.1016/j.celrep.2020.108586

76. Mladenov E, Magin S, Soni A, Iliakis G. DNA double-strand break repair as determinant of cellular radiosensitivity to killing and target in radiation therapy. Front Oncol (2013) 3:113. doi: 10.3389/fonc.2013.00113

77. Wright WD, Shah SS, Heyer WD. Homologous recombination and the repair of DNA double-strand breaks. J Biol Chem (2018) 293:10524-35. doi: 10.1074/jbc.TM118.000372

78. Cheradame L, Guerrera IC, Gaston J, Schmitt A, Jung V, Pouillard M, et al. STING Promotes Breast Cancer Cell Survival by an InflammatoryIndependent Nuclear Pathway Enhancing the DNA Damage Response. bioRxiv (2020). doi: 10.1101/2020.07.11.196790

79. Liu H, Zhang H, Wu X, Ma D, Wu J, Wang L, et al. Nuclear cGAS suppresses DNA repair and promotes tumorigenesis. Nature (2018) 563:131-6. doi: 10.1038/s41586-018-0629-6

80. Jiang H, Xue X, Panda S, Kawale A, Hooy RM, Liang F, et al. Chromatinbound cGAS is an inhibitor of DNA repair and hence accelerates genome destabilization and cell death. EMBO J (2019) 38:e102718. doi: 10.15252/ embj.2019102718

81. Zaki-Dizaji M, Akrami SM, Azizi G, Abolhassani H, Aghamohammadi A. Inflammation, a significant player of Ataxia-Telangiectasia pathogenesis? Inflamm Res (2018) 67:559-70. doi: 10.1007/s00011-018-1142-y

82. Davis T, Kipling D. Werner Syndrome as an example of inflamm-aging: possible therapeutic opportunities for a progeroid syndrome? Rejuvenation Res (2006) 9:402-7. doi: 10.1089/rej.2006.9.402

83. Gratia M, Rodero MP, Conrad C, Bou Samra E, Maurin M, Rice GI, et al. Bloom syndrome protein restrains innate immune sensing of micronuclei by cGAS. J Exp Med (2019) 216:1199-213. doi: 10.1084/jem.20181329

84. Greten FR, Grivennikov SI. Inflammation and Cancer: Triggers, Mechanisms, and Consequences. Immunity (2019) 51:27-41. doi: 10.1016/ j.immuni.2019.06.025

85. Dou Z, Ghosh K, Vizioli MG, Zhu J, Sen P, Wangensteen KJ, et al. Cytoplasmic chromatin triggers inflammation in senescence and cancer. Nature (2017) 550:402-6. doi: 10.1038/nature24050

86. Gluck S, Guey B, Gulen MF, Wolter K, Kang TW, Schmacke NA, et al. Innate immune sensing of cytosolic chromatin fragments through cGAS promotes senescence. Nat Cell Biol (2017) 19:1061-70. doi: 10.1038/ncb3586

87. Yang H, Wang H, Ren J, Chen Q, Chen ZJ. cGAS is essential for cellular senescence. Proc Natl Acad Sci USA (2017) 114:E4612-20. doi: 10.1073/ pnas. 1705499114

88. Deng L, Liang H, Xu M, Yang X, Burnette B, Arina A, et al. STINGDependent Cytosolic DNA Sensing Promotes Radiation-Induced Type I Interferon-Dependent Antitumor Immunity in Immunogenic Tumors. Immunity (2014) 41:843-52. doi: 10.1016/j.immuni.2014.10.019

89. Wan D, Jiang W, Hao J. Research Advances in How the cGAS-STING Pathway Controls the Cellular Inflammatory Response. Front Immunol (2020) 11:615. doi: 10.3389/fimmu.2020.00615

90. Wang H, Hu S, Chen X, Shi H, Chen C, Sun L, et al. cGAS is essential for the antitumor effect of immune checkpoint blockade. Proc Natl Acad Sci USA (2017) 114:1637-42. doi: 10.1073/pnas.1621363114

91. Padovan E, Spagnoli GC, Ferrantini M, Heberer M. IFN-alpha2a induces IP10/CXCL10 and MIG/CXCL9 production in monocyte-derived dendritic cells and enhances their capacity to attract and stimulate CD8+ effector T cells. J Leukoc Biol (2002) 71:669-76. doi: 10.1189/jlb.71.4.669

92. Ohkuri T, Kosaka A, Ishibashi K, Kumai T, Hirata Y, Ohara K, et al. Intratumoral administration of cGAMP transiently accumulates potent macrophages for anti-tumor immunity at a mouse tumor site. Cancer Immunol Immunother (2017) 66:705-16. doi: 10.1007/s00262-017-1975-1

93. Burnette BC, Liang H, Lee Y, Chlewicki L, Khodarev NN, Weichselbaum RR, et al. The efficacy of radiotherapy relies upon induction of type i interferondependent innate and adaptive immunity. Cancer Res (2011) 71:2488-96. doi: 10.1158/0008-5472.CAN-10-2820

94. Sheng H, Huang Y, Xiao Y, Zhu Z, Shen M, Zhou P, et al. ATR inhibitor AZD6738 enhances the antitumor activity of radiotherapy and immune checkpoint inhibitors by potentiating the tumor immune microenvironment in hepatocellular carcinoma. J Immunother Cancer (2020) 8. doi: 10.1136/ jitc-2019-000340 
95. Wang L, Yang L, Wang C, Zhao W, Ju Z, Zhang W, et al. Inhibition of the ATM/Chk2 axis promotes cGAS/STING signaling in ARID1A-deficient tumors. J Clin Invest (2020) 130:5951-66. doi: 10.1172/JCI130445

96. Ahn J, Xia T, Konno H, Konno K, Ruiz P, Barber GN. Inflammation-driven carcinogenesis is mediated through STING. Nat Commun (2014) 5:5166. doi: $10.1038 /$ ncomms6166

97. Chabanon RM, Muirhead G, Krastev DB, Adam J, Morel D, Garrido M, et al. PARP inhibition enhances tumor cell-intrinsic immunity in ERCC1deficient non-small cell lung cancer. J Clin Invest (2019) 129:1211-28. doi: 10.1172/JCI123319

98. Liang H, Deng L, Hou Y, Meng X, Huang X, Rao E, et al. Host STINGdependent MDSC mobilization drives extrinsic radiation resistance. Nat Commun (2017) 8:1736. doi: 10.1038/s41467-017-01566-5

99. Sharma P, Hu-Lieskovan S, Wargo JA, Ribas A. Primary, Adaptive, and Acquired Resistance to Cancer Immunotherapy. Cell (2017) 168:707-23. doi: 10.1016/j.cell.2017.01.017

100. Chen Q, Boire A, Jin X, Valiente M, Er EE, Lopez-Soto A, et al. Carcinomaastrocyte gap junctions promote brain metastasis by cGAMP transfer. Nature (2016) 533:493-8. doi: 10.1038/nature18268

101. Bakhoum SF, Ngo B, Laughney AM, Cavallo JA, Murphy CJ, Ly P, et al. Chromosomal instability drives metastasis through a cytosolic DNA response. Nature (2018) 553:467-72. doi: 10.1038/nature25432

102. Sen T, Rodriguez BL, Chen L, Corte CMD, Morikawa N, Fujimoto J, et al. Targeting DNA Damage Response Promotes Antitumor Immunity through STING-Mediated T-cell Activation in Small Cell Lung Cancer. Cancer Discov (2019) 9:646-61. doi: 10.1158/2159-8290.CD-18-1020

103. Dillon MT, Bergerhoff KF, Pedersen M, Whittock H, Crespo-Rodriguez E, Patin EC, et al. ATR Inhibition Potentiates the Radiation-induced Inflammatory Tumor Microenvironment. Clin Cancer Res (2019) 25:3392403. doi: 10.1158/1078-0432.CCR-18-1821

104. Schoonen PM, Kok YP, Wierenga E, Bakker B, Foijer F, Spierings DCJ, et al. Premature mitotic entry induced by ATR inhibition potentiates olaparib inhibition-mediated genomic instability, inflammatory signaling, and cytotoxicity in BRCA2-deficient cancer cells. Mol Oncol (2019) 13:242240. doi: 10.1002/1878-0261.12573

105. Kim C, Wang XD, Yu Y. PARP1 inhibitors trigger innate immunity via PARP1 trapping-induced DNA damage response. Elife (2020) 9. doi: 10.7554/eLife.60637

106. Xia T, Konno H, Ahn J, Barber GN. Deregulation of STING Signaling in Colorectal Carcinoma Constrains DNA Damage Responses and Correlates With Tumorigenesis. Cell Rep (2016) 14:282-97. doi: 10.1016/ j.celrep.2015.12.029

107. Song S, Peng P, Tang Z, Zhao J, Wu W, Li H, et al. Decreased expression of STING predicts poor prognosis in patients with gastric cancer. Sci Rep (2017) 7:39858. doi: $10.1038 /$ srep39858

108. Parker BS, Rautela J, Hertzog PJ. Antitumour actions of interferons: implications for cancer therapy. Nat Rev Cancer (2016) 16:131-44. doi: 10.1038/nrc.2016.14

109. Xia L, Tan S, Zhou Y, Lin J, Wang H, Oyang L, et al. Role of the NFkappaBsignaling pathway in cancer. Onco Targets Ther (2018) 11:2063-73. doi: 10.2147/OTT.S161109
110. Chonov DC, Ignatova MMK, Ananiev JR, Gulubova MV. IL-6 Activities in the Tumour Microenvironment. Part 1. Open Access Maced J Med Sci (2019) 7:2391-8. doi: 10.3889/oamjms.2019.589

111. Aglipay JA, Lee SW, Okada S, Fujiuchi N, Ohtsuka T, Kwak JC, et al. A member of the Pyrin family, IFI16, is a novel BRCA1-associated protein involved in the p53-mediated apoptosis pathway. Oncogene (2003) 22:89318. doi: 10.1038/sj.onc. 1207057

112. Tawara H, Fujiuchi N, Sironi J, Martin S, Aglipay J, Ouchi M, et al. Loss of p53-regulatory protein IFI16 induces NBS1 leading to activation of p53mediated checkpoint by phosphorylation of p53 SER37. Front Biosci (2008) 13:240-8. doi: 10.2741/2674

113. Fujiuchi N, Aglipay JA, Ohtsuka T, Maehara N, Sahin F, Su GH, et al. Requirement of IFI16 for the maximal activation of p53 induced by ionizing radiation. J Biol Chem (2004) 279:20339-44. doi: 10.1074/ jbc.M400344200

114. Crowl JT, Gray EE, Pestal K, Volkman HE, Stetson DB. Intracellular Nucleic Acid Detection in Autoimmunity. Annu Rev Immunol (2017) 35:313-36. doi: 10.1146/annurev-immunol-051116-052331

115. Li XD, Wu J, Gao D, Wang H, Sun L, Chen ZJ. Pivotal roles of cGAS-cGAMP signaling in antiviral defense and immune adjuvant effects. Science (2013) 341:1390-4. doi: 10.1126/science.1244040

116. de Oliveira Mann CC, Orzalli MH, King DS, Kagan JC, Lee ASY, Kranzusch PJ. Modular Architecture of the STING C-Terminal Tail Allows Interferon and NF-kappaB Signaling Adaptation. Cell Rep (2019) 27:1165-1175 e5. doi: 10.1016/j.celrep.2019.03.098

117. Vila IK, Fretaud M, Vlachakis D, Laguette N, Langevin C. Animal Models for the Study of Nucleic Acid Immunity: Novel Tools and New Perspectives. J Mol Biol (2020) 432:5529-43. doi: 10.1016/j.jmb.2020.08.016

118. Murira A, Lamarre A. Type-I Interferon Responses: From Friend to Foe in the Battle against Chronic Viral Infection. Front Immunol (2016) 7:609. doi: 10.3389/fimmu.2016.00609

119. Schwartz DM, Kanno Y, Villarino A, Ward M, Gadina M, O'Shea JJ. JAK inhibition as a therapeutic strategy for immune and inflammatory diseases. Nat Rev Drug Discov (2017) 17:78. doi: 10.1038/nrd.2017.267

120. Motwani M, Pesiridis S, Fitzgerald KA. DNA sensing by the cGAS-STING pathway in health and disease. Nat Rev Genet (2019) 20:657-74. doi: 10.1038/s41576-019-0151-1

\section{Conflict of Interest: JM was employed by Azelead.}

The remaining authors declare that the research was conducted in the absence of any commercial or financial relationships that could be construed as a potential conflict of interest.

Copyright $\odot 2021$ Taffoni, Steer, Marines, Chamma, Vila and Laguette. This is an open-access article distributed under the terms of the Creative Commons Attribution License (CC BY). The use, distribution or reproduction in other forums is permitted, provided the original author(s) and the copyright owner(s) are credited and that the original publication in this journal is cited, in accordance with accepted academic practice. No use, distribution or reproduction is permitted which does not comply with these terms. 